\title{
Mulier Striga, Documento atribuido a Bartolo de Sassoferrato. ¿Primera PIEdra medieval Para EL RETRATO DE LA BRUJA?
}

\author{
Eva Lara Alberola ${ }^{1}$ \\ Universidad Católica de Valencia
}

Recibido: 7 de diciembre de 2019

Aceptado: 8 de septiembre de 2020

\begin{abstract}
Resumen
En este artículo profundizamos en el consilium Mulier striga, atribuido a Bartolo de Sassoferrato y fechado entre 1331-1334. Contribuimos a difundir el hecho de que se trata de una falsificación y que su autor fue Giovanni Battista Piotti, jurista del siglo XVI; cuestión apenas conocida por muchos especialistas que siguen presentando el texto como medieval. Por otra parte, analizaremos pormenorizadamente el retrato de la bruja presente en este escrito, no abordado por los expertos, con el fin de determinar si la imagen ofrecida es anacrónica, como sucede con otros aspectos del documento, o se ajusta a la primera mitad del siglo XIV.
\end{abstract}

\section{Palabras clave}

Sassoferrato, Mulier Striga, Medievo, Piotti, brujería

\begin{abstract}
In this article we delve into de consilium entitled Mulier striga, attributed to Bartolo de Sassoferrato and dated between 1331-1334. We contribute to spread the fact it is a forgery and that its author was Giovanni Battista Piotti, a sixteenth-century lawyer, a fact hardly known by many specialists who continue to present the texto as medieval. On the other hand, we will analyze in detail the portrait ot the witch present in this work, never examined by the experts before, in order to determine whether the picture offered is anachronistic, as it happens with other aspects of the document, or matches the beliefs of the first half of the fourteenth century.
\end{abstract}

\section{Keywords}

Sassoferrato, Mulier Striga, Middle Ages, Piotti, witchcraft

\footnotetext{
1 Facultad de Magisterio y Ciencias de la Educación. Dpto. Lengua y Literatura. Universidad Católica de Valencia “San Vicente Mártir”. c/ Sagrado Corazón, 5. 46110 Godella (Valencia). Correo electrónico: eva. lara@ucv.es. ORCID: https://orcid.org/0000-0001-5063-5424. El presente trabajo se inscribe en las actividades del Proyecto de I+D del Programa Estatal de Generación de Conocimiento (MCIU/FEDER) PGC2018095757-B-I00:Magia, Épica e Historiografia Hispánicas: Relaciones Literarias y Nomológicas II, dirigido por el doctor Alberto Montaner Frutos; y en el Proyecto I+D para grupos emergentes Figuras de lo insólito en la literatura de márgenes: fascinación y horror en el mundo hispánico (XVII-XIX) (GV/2020/207), financiado por la Conselleria d'Innovació, Universitats, Ciència i Societat Digital, dirigido por el doctor Juan Gomis Coloma
} 


\begin{abstract}
Sommario
In questo articolo approfondiamo nel consilium Mulier striga, attibruito a Bartolo da Sassoferrato e datato tra il 1331 e il 1334. Contribuiamo a diffondere il fatto che si tratta di una falsificazione e il suo autore è Giovanni Battista Piotti, giurista del XVI secolo; problema a malapena conosciuto da molti specialisti che continuano a presentare il testo come medievale. D'altra parte, analizzeremo in dettaglio il ritratto della strega presente in questo scritto, non affrontato dagli esperti, al fine di determinare se l'immagine offerta è anacronistica, come nel caso degli altri aspetti del documento, o è adattata a la prima metà del XIV secolo.
\end{abstract}

\title{
Parole chiave
}

Sassoferrato, Mulier Striga, Medioevo, Piotti, stregoneria

\section{Introducción}

El objeto de la presente investigación es el consilium conocido como Mulier Striga, atribuido al afamado jurista medieval Bartolo de Sassoferrato y fechado en torno a los años 1331-1334. En un intento de ahondar en el primigenio retrato de la bruja, en el marco de una investigación más amplia acerca de los antecedentes de la literatura de terror sobrenatural (en concreto aquellos de temática mágica), ${ }^{2}$ decidimos explorar lo que la Edad Media ofrecía al respecto. Hay que tener en cuenta que existen tanto antecedentes literarios propiamente dichos, como lo que hemos denominado literatura vivencial de terror, que incluiría materiales tales como documentos jurídicos, actas de procesos, tratados de demonología y brujería, manuales de inquisidores, etc. En España y en el Medievo, no contamos con textos literarios cuya figura central (o incluso marginal) sea una bruja como tal; por ello, solo podemos acercarnos a esta cuestión a partir de otra clase de materiales, tales como los que hemos mencionado.

La razón por la que hemos escogido Mulier Striga es su presunta antigüedad (1331-1334) y el papel que le atribuyen los especialistas en diferentes estudios sobre la historia de la brujería. Este concilio ocupa un lugar privilegiado en la cadena de transmisión de la imagen brujeril y del castigo que esta criatura merece. Se trataría de un escrito anterior al célebre Directorium inquisitorum de Nicolau Eymerich (1370), que aún no se centra en la brujería en sí, solo en los distintos tipos de pacto diabólico y en el hecho de si estos pueden considerarse herejía ${ }^{3}$ (hay que esperar a $1435-1438$ para que el Formicarius de Johannes Nider vea la luz, un tratado que sí se detiene de forma específica y detallada,

2 El maestro Lovecraft justifica, con sus palabras, el estudio que estamos llevando a cabo, puesto que expone que: "El terror cósmico [...] fue, sin duda, un rasgo destacado de la rebuscada magia ceremonial, con sus rituales de invocación de demonios y espectros" (LoveCRAFT, El horror sobrenatural, p. 33). Señala también que: "El predominio de la tradición del horror en Occidente se debió [...] en gran parte a la presencia encubierta [...] de un culto espantoso de adoradores nocturnos. [...] Este culto se convirtió en fuente de un enorme acervo de leyendas sobre brujería" (El horror sobrenatural, p. 34). Todo lo relativo a la magia negra y la brujería conecta, de uno u otro modo, con lo terrorífico.

3 Eymerich; PeÑa, El manual de los inquisidores. A pesar de que hay estudiosos (como María Lara, Pasaporte de bruja) que consideran que este manual se centra en la brujería, esto no es así. Eymerich 
en su Libro V, en la brujería con múltiples ejemplos). ${ }^{4}$ Además, llama la atención que la fecha de composición coincida, con pocos años de diferencia, con la promulgación de la bula del Papa Juan XXII Super illius specula, de $1326 .{ }^{5}$ Se considera, por tanto, el documento jurídico más antiguo redactado contra una bruja ${ }^{6}$. Pensemos, además, que sería el texto de transición entre la doctrina propia del Canon episcopi, que toma por ilusiones diabólicas todo lo referente a las mujeres que vuelan de noche tras Diana o Herodiade, ${ }^{7}$ creencia que se refleja igualmente en el Policraticus de Juan de Salisbury, ${ }^{8}$ y el primer tratado que ahonda en estas cuestiones y les da crédito, el Formicarius.

Partiremos de las siguientes cuestiones: ¿es Mulier Striga el documento que sirve como primera piedra para construir la imagen de la bruja? ¿Cuál es el retrato que nos ofrece el texto? ¿Es realmente un escrito tan temprano? ¿Dónde radica su originalidad?

\section{Mulier striga: una sospechosa bruja medieval}

\subsection{Anatomía del consilium}

Para comenzar y antes de profundizar en otras cuestiones más complejas, resulta fundamental acercarse a la imagen de la bruja que se presenta en el texto, teniendo en cuenta que este se redacta como respuesta a la petición de consejo del obispo de Novara, en relación con una bruja de Orta. ${ }^{9}$

A lo primero que se hace alusión es al vuelo, como un acto propio de esta criatura frente al resto de categorías mágicas. Quizás por ello aparece en primer lugar. Inmediatamente, se identifica a la bruja con la lamia latina, hecho que no llama la atención porque ya Juan de Salisbury hablaba de lamias en relación con aquellas mujeres que seguían un cortejo nocturno (precisamente, refleja la creencia de que se sacrificaban niños a esas lamias). Y, acto seguido, se reclama la pena máxima para ella, la hoguera: "Mulier striga, de qua agitur, sive Latine loquendo lamia, deber tradi ultimo supplicio, \& igne cremari". ${ }^{10}$

Lo que viene a continuación es una justificación de lo enunciado. Hace falta argumentar la petición de la pena capital. La bruja merece tal punición porque renuncia a Cristo y al bautismo: "Fatetur enim Christo, \& baptismati renunciasse, ergo debet mori","

no habla todavía de brujería. Esta confusión proviene de la no diferenciación entre hechicería y brujería. Para ahondar en estas cuestiones, véase Montaner y LARA, "Magia, hechicería, brujería").

4 NIDER, Formicarius.

5 Troncarelli, Le streghe, pp. 95-96.

6 Centini, Las brujas en el mundo.

Concilvum Ancyrarum (314), pp. 1.476-1.477.

8 Caro Baroja, Las brujas y su mundo, p. 90. Tomado de Juan de Salisbury, Policraticus (Leyden), 1639, p. 83.

9 Agradezco la asistencia prestada por el dr. Julio Alonso Asenjo y el dr. Alberto Montaner Frutos en relación con el latín del texto.

10 Pseudo-sassoferrato, Consilia, p. 184.

11 Pseudo-sassoferrato, Consilia, p. 184. 
pues así lo dicen las Sagradas Escrituras, a las que el autor alude, y la ley evangélica prevalece sobre todas. Igualmente, profana objetos sagrados: "Item confitetur dicta striga, sive lamia, se crucem fecisse ex paleis, \& talem crucem pedibus conculcasse, $\&$ crucem ipsam dedita opera fecisse, ut illam pedibus coculcaret, \& suppeditaret, ergo ex hoc solo etiam debet mori puniri", ${ }^{12}$ y hace referencia a las leyes canónicas, según J. Hansen ${ }^{13}$ los Sextus decretal. L. 1 tit. 16. C. 2 (P. Gregorio X, a. 1274), es decir, el decreto de Gregorio X del Concilio Lugdunense; documento en el que se pide una pena dura para el delincuente, en correspondencia con el delito cometido.

La striga, en tercer lugar, adora al diablo: "Ulterius haec striga confitetur se adorasse diabolum illi genua flectendo, ergo debet capitaliter \& ultimo affici supplicio"14 y esta vez alude a la Lex cornelia de sicariis et veneficis. Igualmente, esta lamia "Confitetur etiam pueros tactu strigasse, \& fascinasse adeo quod mortui fuerunt, \& de eorum morte constat, \& matres super hoc dederunt querelas, ergo ipsa striga tanquam homicida debet mori" ${ }^{15}$ y se vuelve a apelar a la autoridad de la Lex Cornelia de sicariis et veneficis. Continúa el jurista exponiendo: "Audivi enim a sacris quibusdam Theologis has mulieres, quae lamiae sive strigae nuncupantur, tactu, vel visu posse nocere, et usque ad mortem fascinando homines, seu pueros, ac bestias cum habeat animas infectas, quas demoni vouerunt". ${ }^{16}$ No se cita a ninguno de tales teólogos. Tampoco habla en este caso de confesión de la bruja de Orta, sino de aquello que los expertos comentan acerca de las capacidades de estas mujeres, que pueden dañar e incluso matar solo a través de la mirada y el tacto, a hombres, niños y animales, siempre para servir al demonio. Y remite esta vez a la Égloga 3 de Virgilio, dado que aquello que los poetas recogen es lícito. Nuevamente, reivindica la pena de muerte para esta criatura homicida, aunque en referencia a estos últimos maleficios y su posibilidad real remite a la Santa Madre Iglesia y a los sacros teólogos.

En consecuencia, recomienda a Ioannis Piotti, obispo de Novara, en relación con el caso de la bruja, que le aplique la pena capital, y apunta como referencia a los "Decretali c. Vergentis de haeretic."; según Hansen, ${ }^{17}$ "Decretal. L. 5. tit. 7 c. 10 ", del Papa Inocencio III y 1212. Se trata de la bula Vergentis in senium, en la que Inocencio III aplica el derecho romano contra los herejes y asimila la herejía al crimen de lesa majestad y por ello les pueden ser confiscados los bienes o pueden ser excluidos de las funciones públicas o desheredados. ${ }^{18}$ Jorge Blaschke habla de decreto por medio del cual se establece para los herejes la misma pena prevista en el derecho romano para el crimen de traición. ${ }^{19}$ Del mismo modo, apela a "c. ad abolendam de haereticis", o sea, Decretal. l. 5 tit. 7 c. 9 (Lucius III a. 1184). Este Papa, Lucio III, promulga, en

\footnotetext{
Pseudo-sassoferrato, Consilia, p. 184.

Hansen, Quellen, p. 64.

Pseudo-sassoferrato, Consilia, p. 184.

Pseudo-sassoferrato, Consilia, p. 184.

Pseudo-sassoferrato, Consilia, p. 184.

Hansen, Quellen, p. 65, n. 3.

Zerner, Diccionario razonado, p. 335.

BlaschKe, El enigma medieval, p. 202.
} 
el Concilio de Verona de 1184, el decreto Ad Abolendam para reprimir la herejía. ${ }^{20}$ También se hace referencia a "l. 3. ibi, tu magis scire potes, ff. de testi.", es decir, Corpus iuris civilis P. III, sect. 2 ad l. III t. 27 Spec. de testibus $3 .{ }^{21}$ Para finalizar, leemos: "Ubi autem concederetur, eam fuisse homicidam, ex poenitentia non evitaret poenam mortis huius seculi ff. de furt. 1. qui ea mente; sed (ut dixi) super homicidio remitto me ad ecclesiam sanctam". ${ }^{22}$ En relación con "[...] qui ea mente", explica Hansen $^{23}$ que el escrito se refiere nuevamente a "Corpus iuris civilis P. III sect. 2 ad l. IV t. 1 Spec. de furtis 65 " y, con respecto a la remisión a la Santa Madre Iglesia, menciona este mismo estudioso un tratado de 1320, denominado Tractatus seu forma procedendi contra de haeresi inquisitos. ${ }^{24}$

Eso sí, se contempla la posibilidad del perdón o, al menos, se deja en manos del juez o el inquisidor ser compasivo en caso de que la acusada se arrepienta:

"Sed an, ubi ista striga veniat ad poenitentiam et ad catholicam fidem revertatur, errore suum parata publica abiurare ad arbitrium don Ioannis de Piotis episcopi Novariae, debeat eidem quoad poenas temporales et mortem huius seculi parci (et dico quod, si incontinenti post deprehensionem errores revertatur ad fidem et signa poenitentiae in ea appareant), debet in hoc casu eidem parci proculdubio c. ad abolendam de haereticis. Et si non sit incontinenti, sed cum intervallo, iudicis arbitrio relinquendum puto, an signa verae poenitentiae in ea appareant, et tunc eidem debeat parci, alias non, si timore poenae poeniteat. Hoc autem d. episcopi de Piotis et d. inquisitoris arbitrium collocandum dico 1. 3. ibi, tu magis scire potes, ff. de testi. Ubi autem concederetur, eam fuisse homicidam, ex poenitentia non evitaret poenam mortis huius seculi ff. de furt. l. qui ea mente; sed (ut dixi) super homicidio remitto me ad ecclesiam sanctam". 25

Resalta la pena capital sobre todo en el caso de que la bruja haya cometido homicidio y, en todo caso, remite a la doctrina de la Iglesia, dado que él puede hablar como jurista, mas no como teólogo. En Biblioteca lamiarum ${ }^{26}$ encontramos una entrada dedicada a Mulier striga, en la cual se señala, de forma muy general, que el tono del escrito va suavizándose paulatinamente, el autor no se pronuncia sobre la posibilidad de matar a través de la vista y el tacto, y finalmente se inclina por el perdón en el caso de que la bruja se arrepienta

\footnotetext{
ZERnER, Diccionario razonado, p. 334.

Hansen, Quellen, p. 66, n. 5.

Pseudo-sassoferrato, Consilia, p. 184.

Hansen, Quellen, p. 66, n. 1.

HANSEn, Quellen, p. 66, n. 2.

5 Pseudo-sassoferrato, Consilia, p. 184.

26 VV.AA., Biblioteca lamiarum, p. 96.
} 
y abjure públicamente. ${ }^{27}$ En este hecho insisten tanto Kieckhefer ${ }^{28}$ como Santangelo, ${ }^{29}$ y ambos hablan de la actitud moderada del autor, frente a lo expresado por otros expertos en los que recalaremos más adelante. La última especialista, de hecho, resalta por un lado el rechazo a la brujería presente en el documento, a la que se aplica la pena capital y, por otro, cierto escepticismo al suspender el juicio y remitir a los teólogos y sus afirmaciones sobre estas mujeres. Por otra parte, Semeraro ${ }^{30}$ expone la existencia de estas posturas, frente a lo que afirman la mayoría de los especialistas, que es la imposición de la pena capital de una manera contundente, y él se limita a señalar que este Pseudo-Bartolo remite a la autoridad de la Iglesia en cuestiones tales como la correspondencia entre el acto mágico y la muerte de una persona, para que esta institución sea la que determine la viabilidad o no del crimen. No va más allá el autor, no termina de posicionarse, pero hace evidente que hay quien sostiene el escepticismo por parte del escritor del consilium.

\section{2. ¿Al margen de la ley?}

Todas las leyes que se mencionan en el documento, que son pocas y en ocasiones citadas de forma vaga, son siempre anteriores a la supuesta fecha de composición del texto, 13311334, afirmación que puede resultar llamativa, en tanto no sería posible que un jurista del siglo XIV citara leyes posteriores al momento de composición del texto, a menos que en realidad el escrito no sea de tal fecha, sino bastante posterior. No se menciona, y esto resulta chocante, la Bula Super illius specula de Juan XXII, de 1326, que focaliza de forma específica en los agentes de la magia, aunque quizás no interesaba traerla a colación, dado que la pena que proponía para tales oficiantes era la excomunión y solamente en casos graves de reiteración se consideraba la posibilidad de aplicar el mismo castigo que a los herejes. Pensemos que la brujería no se menciona en uno solo de los decretos aquí aducidos, en todo caso aparece la magia en un sentido general. Habrá que esperar, además, a 1370, cuando ve la luz el Directorium inquisitorum de Nicolau Eymerich, para hallar información detallada acerca los distintos tipos de pacto diabólico y de si estos pueden asimilarse a la herejía. Evidentemente, la magia y la hechicería se ven recogidas en estas consideraciones. ${ }^{31}$ Además, en Mulier striga se cita alguna ley que actúa contra la herejía, pero que no propone todavía la pena de muerte para este crimen. Ante todo, lo que se detecta es un gran esfuerzo por imponer la pena capital en este caso a toda costa, lo cual levantó las sospechas de algunos expertos, como veremos más adelante.

\footnotetext{
27 Esta postura cuadraría con el contexto de presunta composición del documento, ya que Martín Pérez, en el Libro de las confesiones (1312-1317), todavía recriminaba a aquellas personas que creían en la posibilidad de esta clase de maleficios a través, por ejemplo, de la vista (predomina, por tanto, la incredulidad al respecto). La moderación o cautela del autor del texto casaría perfectamente con la concepción de la época. Eso sí, la duda razonable acerca de esta clase de actos mágicos mostraría una transformación de las creencias.

28 KieCKHefer, La magia en la Edad Media, p. 192.

29 Santangelo, "Mulier-striga", pp. 122-123.

30 Semeraro, Il tribunale del Santo Officio, p. 86.

31 Eymerich; PeÑa, El manual de los inquisidores.
} 
Es cierto que la ley medieval contemplaba el castigo a los practicantes de la magia en muchas ocasiones, aunque esto no era en absoluto nuevo. Ya las Sagradas Escrituras condenaban la adivinación y la nigromancia (Éxodo, 22, 17; Levítico, 19, 31-32 y Levítico, 20, 6 y 27). Igualmente, el Código Hammurabi, en 1753 a. C., castigaba la hechicería y del mismo modo sucedía con el Código de las doce tablas (451-450 a. C.) y con la Lex Cornelia de sicariis et veneficiis (81 a. C.). Constantino, por su parte, había dedicado una ley a los arúspices, para quienes defendía la pena de muerte; y Constancio, Valentiniano y Valente fueron todavía más fanáticos, por lo que la legislación contra la magia aumentaba. ${ }^{32}$

El rechazo de lo mágico se puede observar también en los Santos Padres, como San Agustín, y la Iglesia condenaba estas artes en el Concilio de Ancira (314), que ponía el foco de atención en los oficiantes de magia negra y causantes de maleficio; el Concilio de Elvira (340), el cual preveía la punición para aquellos que causaran la muerte mediante magia; y el Concilio de Laodicea (363-364), que ordenaba la excomunión para quien se dedicara a las artes mágicas. Desde el siglo IV, además, se hallan prohibiciones, por ejemplo, contra los arúspices en el Código Teodosiano, y se pueden encontrar diversas prohibiciones y puniciones en el Concilio de Vannes (461), el Concilio Visigodo de Agde (506), de Orleans (511) y Auxerre (518). En el II Concilio de Braga (572) se solicitaba penitencia a quien consultara a adivinos o sortílegos, y también se encuentran contenidos similares en el Concilio Narborense (589), en los sínodos franceses de 511, 533, 541, 573 y 603; o el IV y V Concilio de Toledo (633 y 636). El XII Concilio de Toledo (681) focalizaba en los adoradores de ídolos, igual que el XVI Concilio de Toledo (693), pero ninguno de ambos preveía la pena de muerte, aunque sí la corrección de estas personas engañadas por el diablo. El Edicto de Luitprando (727) hablaba de demonios dedicados a raptar niños y a chupar su sangre y relacionaba este hecho con una pervivencia del paganismo.

Carlomagno, hacia 755, prohibió la astrología, los augurios, las predicciones de lo que está por venir y la interpretación de los sueños. En el Concilio de París de 829 se daba crédito a los actos ejecutados por los magos y hechiceros, a quienes había que escarmentar. Convivían aquellos que creían en estos hechos y los que no los consideran posibles, como Agobardo, obispo de Lyon (779-840). Posteriormente, el texto que

\footnotetext{
32 Según Salinas de FríAs ("Tradición y novedad en las leyes"), Constancio abrió fuego contra el paganismo en una ley del año 341, que fue renovada en 346, 353, 356, 357 y 358. Se pretende combatir la magia en todas sus formas, pues se considera una práctica pagana. Igualmente, Valentiniano y Valente prohibieron, en el año 364, las "nefarias preces, magicos apparatus" y los "sacrifica funesta" bajo pena capital. Teodosio, por su parte, emprendió la gran batalla contra las artes mágicas que eran, cada vez más, cosa de las clases bajas. Resulta llamativo que una ley de Graciano, Valentiniano y Teodosio (381 y reiterada en los años 385 y 391) prohibiera la realización de sacrificios nocturnos y la adivinación. Otra ley de Teodosio, Arcadio y Honorio, de 392, incidía nuevamente en los sacrificios, entre otras cuestiones, como el culto a los lares y penates. Se daba una confusión entre ritos religiosos y magia. Escasas fueron, sin embargo, las leyes de los sucesores de Teodosio: Arcadio, Honorio y Teodosio II, que se centraron más en la herejía, castigada con la muerte. De hecho, la ley de Honorio y Teodosio II, que cierra el Código Theodosiano con leyes acerca de los malefici y mathematici, es más benévola que las anteriores, pues les otorga el perdón. No hay todavía, como vemos, una equiparación de los magos y hechiceros con los herejes.
} 
supone un hito es el conocidísimo Canon episcopi, el cual tomaba todas las ideas ahí reflejadas, en torno al cortejo de Diana, como ilusiones diabólicas a las que no había que dar ningún crédito. El Decreto de Bucardo de Worms (1025) seguía la misma línea marcada por el Canon episcopi. Pensemos que estos dos últimos textos se hacen eco de unas creencias distintas a las plasmadas en la legislación detallada aquí. ${ }^{33}$ El Decreto de Graciano, por su parte, en 1138 sostenía la existencia de una relación estrecha entre la magia y hechicería y el diablo. ${ }^{34} \mathrm{Y}$ este hecho se hace más patente en la bula Super Illius Specula del Papa Juan XXII (1326).

Resulta de interés que, poco antes de la promulgación de la mencionada bula, Federico III de Sicilia, aconsejado por el médico Arnau de Vilanova, en sus Ordinationes, incluya un epígrafe contra los magos, los adivinos y los hechiceros, en el que condena a muerte a estos oficiantes y se suma, además, la deportación de los incitadores. ${ }^{35}$ Como bien afirma Giralt:

"Hasta las primeras décadas del siglo XIV se ponía el énfasis en la idea de que los nigromantes eran víctimas del engaño por parte del diablo, y en el consiguiente escepticismo en la efectividad de los rituales. Posteriormente, pasaría a primer plano la creencia en la existencia real del pacto con el diablo, cuya formulación se convertiría en canónica con Tomás de Aquino y que implicaría una sumisión voluntaria y absoluta al diablo y la condena de los nigromantes y de las brujas por herejía". ${ }^{36}$

En el marco de este complicado proceso, resulta inviable (aun teniendo en cuenta que ya se había hablado de castigo capital en algunas leyes en relación con la magia), en la supuesta fecha de composición del consilium que nos ocupa, que se defienda tan a ultranza la pena de muerte para la brujería, aún en vías de consolidación (todavía no aparece en la documentación como un fenómeno independiente, al margen de otras manifestaciones mágicas). ${ }^{37}$

\footnotetext{
33 Se refieren a un grupo de mujeres que, presuntamente, volarían por las noches siguiendo a diosas como Diana o Herodiade. No presentan un carácter maléfico en el Canon episcopi, pero quizás por su naturaleza pagana se relacionan con lo diabólico, aunque en este momento solo como ilusión causada por el demonio, puesto que se considera imposible que estas féminas surcaran los cielos realmente. De hecho, se condena la creencia en este cortejo. En el Policraticus, que sigue todavía esta misma doctrina y no da crédito a este séquito nocturno, vemos una evolución de este, ya que dichas mujeres exhiben comportamientos punibles, tales como devorar niños. Y se da ya, como hemos dicho, un acercamiento de estas seguidoras de Diana a las temibles criaturas que se alimentan de infantes.

34 Koning, Historia del satanismo; Salinas de Frías, "Tradición y novedad en las leyes"; MÉrida, El gran libro de las brujas; LARA AlBerola, Hechiceras y brujas; Centini, Las brujas en el mundo.

35 Giralt, "Magia y ciencia", p. 35.

36 Giralt, "Magia y ciencia", p. 53.

37 Véase Montaner y LARA, "Magia, hechicería, brujería".
} 


\section{Un giro en la investigación: ¿es Mulier striga un texto medieval?}

Una vez presentado el texto y desgranadas las principales características que adornan a la bruja, nos desviamos de nuestro propósito primero relacionado con este escrito como primera piedra medieval para la literatura de terror sobrenatural, y nos detenemos en otro asunto de mayor importancia, lo cual altera el objetivo de nuestra indagación y reorienta nuestro estudio, apuntando en otra dirección, que será la que finalmente desarrollaremos en este artículo.

Numerosos especialistas han hecho referencia a Mulier striga como un documento de carácter jurídico de la primera mitad del siglo XIV y de Bartolo de Sassoferrato, entre ellos: Hansen (1901), ${ }^{38}$ Lea y Howland (1939), ${ }^{39}$ Bonomo (1959) ${ }^{40}$ Troncarelli (1983), ${ }^{41}$ Abbiati-Agnoletto-Lazzati (1984), ${ }^{42}$ Kieckhefer (1992), ${ }^{43}$ Massimo Centini (2012) ${ }^{44} \mathrm{o}$ Marina Montesano (2016). ${ }^{45} \mathrm{Y}$ en 1994, Biblioteca lamiarum había dedicado también una entrada a Mulier striga, concilio que se consideraba el primer escrito italiano que hace referencia a un proceso por brujería y se daba como fecha aproximada 1340 . De hecho, en el Convegno Nazionale di Studi Storico-Antropologici de 2004, las contribuciones de Massimo Centini y Giovanni Giorgetta consideraban Mulier striga como un concilio de Sassoferrato y medieval. ${ }^{46}$

Sin embargo, antes de que la crítica aludiera a este concilio y le otorgara un papel fundamental, otros intelectuales ya lo habían hecho. Quizás el más destacable sea Martín del Río, quien en sus Disquisitionum magicarum de 1599, al hablar de la pena que merecen los maléficos, se refería a Mulier striga, de Bartolo de Sassoferrato, escrito contenido en el Consilia criminalia ... editado por Ziletti (1566). ${ }^{47}$ Del mismo modo, Pierre de Lancre, en su Tableau de l'inconstance des mauvais anges et demons de 1612, cita el Mulier striga de Bartolo de Sassoferrato. ${ }^{48}$ Son dos muestras muy representativas de la inclusión de tal referencia en los tratados demonológicos. Con ello se iniciaría esa cadena se transmisión que Beccaria ${ }^{49}$ considerará un auténtico virus.

\footnotetext{
Hansen, Quellen.

9 Lea y Howland, Material toward a history.

Bonomo, Caccia alle streghe.

1 Troncarelli, Le streghe. en realidad se edita en 1959 .

43 Kieckhefer, La magia en la Edad Media.

44 Centini, Las brujas en el mundo.

45 Montesano, "Le rôle de la culture classique".

46 En esto se detiene Beccaria, "Giovanni Battista Piotti”, p. 289.

47 Río, Disquisitionum magicarum, Libro V, sec. XVI, p. 813.

48 LANCRE, Tableau de l'inconstance, Libro VI, cap. 8, p. 542.

49 Beccaria, "Giovanni Battista Piotti".
}

42 AbBiati; Agnoletto; Lazzati, La stregoneria. De todas estas referencias da cuenta también BECCARIA, "Giovanni Battista Piotti", p. 289. Sin embargo, hallamos algún error en las fechas de las obras de estos expertos, pues se data el libro de Troncarelli en 1903, lo que suponemos una errata por 1983; se facilita 1957 para el trabajo de Lea y Howland (y se señala que su material es de los años 50), pero la primera edición es de 1939; y se habla del estudio de Bonomo como un producto de la década de los 70 cuando 
Y no podemos dejar de mencionar a Jacob Grimm y su Deutsche Mythologie (1835), obra en la que, dentro de la sección dedicada a la magia y en concreto a "la novia del diablo", hallamos una referencia al texto que nos interesa de Bartolo de Sassoferrato al realizar un repaso histórico de la persecución brujeril..$^{50}$ Del mismo modo, aparece este consilium recogido, con los mismos datos que hemos ido repitiendo, en Memorie dell'I. R. Istituto Lombardo di scienze lettere ed arti de $1845,{ }^{51}$ por poner otro ejemplo anterior al siglo XX.52

No obstante, Girolamo Tartarotti, en su Congresso notturno delle lamie libri tre de 1749, al detenerse en lo que él llama doctrinas falsas, alude a Martín del Río y su mención del Mulier striga, criticando que Del Río no dudara de la autenticidad del texto. ${ }^{53}$ Comienza aquí el cuestionamiento de la veracidad de esta producción, aunque, como veremos, ha habido que esperar mucho tiempo para que los especialistas profundizaran en este asunto.

Nos detendremos, a este respecto, en un breve estado de la cuestión. Norman Cohn, en 1975, ya reparó en la existencia de varias falsificaciones textuales que remitían a cazas de brujas masivas durante la Edad Media. ${ }^{54}$ Entre los documentos que Cohn considera falsos se encontraría Mulier striga. Izbicki y Lally, ${ }^{55}$ en 1991, se centraban en los muchos problemas de autoría que se asociaban a la producción de Bartolo de Sassoferrato y, en el mismo año, Mario Ascheri aportaba varios argumentos, que veremos a continuación, para defender que Mulier striga y otros consilia serían una falsificación y ya apuntaba como autor real de esos apócrifos a Giovanni Battista Piotti, hombre también de leyes del siglo XVI. ${ }^{56}$ Este trabajo de Ascheri resulta una gran aportación porque presenta datos en firme y se apunta ya al que se considera hoy en día el fasificador de varios consilia atribuidos a Sassoferrato. Gaetano Colli, en 1996, habla de los problemas que presentan, en general, los documentos jurídicos medievales, dado que no se publicaban de manera autónoma, en el momento de su composición, a veces por su carácter breve, y muchos pasaban de manuscrito a la imprenta en las primeras décadas del siglo XVI. Otro inconveniente que plantea este estudioso es la correcta atribución de los autores a las obras, y resalta precisamente las falsificaciones editoriales en ese paso de manuscrito a texto impreso en la decimosexta centuria, sobre todo. ${ }^{57}$ En 2003, Martino Semeraro ya presenta Mulier striga como una muy probable falsificación, atendiendo a las aportaciones de Mario Ascheri. ${ }^{58}$ Mattone, en 2007, vuelve sobre la idea de que

\footnotetext{
50 Grimm, Deutsche Mythologie,Vol. III, p. 1066.

51 VV. AA., Memorie dell'I. R., p. 279.

52 Tengamos en cuenta que, según Beccaria (“Giovanni Battista Piotti”, p. 295), en 1800 Pertile publica la Storia del diritto italiano, en la que se integraban los consilia apócrifos que había incluido Ziletti en su Consilia criminalia.

53 Tartarotti, Congresso notturno, Libro III, cap. 10, sec. IX, p. 276.

54 Cohn, Los demonios familiares, pp. 168-192.

55 IZBICKI y LALLY, "Texts attribuited to Bartolo".

56 Ascheri, "Streghe e devianti".

7 Colli, "Attribuuntur Bartolo".

58 Semeraro, Il tribunale del Santo Officio.
} 
Giovanni Battista Piotti es probablemente quien escribió estos textos ${ }^{59} \mathrm{y}$, en el mismo año, Zendri reivindica nuevamente la falsa atribución del consilium, aunque esta no contradice el importante papel que este escrito posee en relación con la brujería ${ }^{60} \mathrm{En}$ 2008, Nico Ottaviani ${ }^{61}$ reconoce que existe unanimidad en cuanto a la falsa autoría y, en 2013, Beccaria aporta una proposición totalmente justificada y repleta de detalles acerca de Giovanni Battista Piotti, que sería quien falseó los documentos. ${ }^{62}$ Llama, por tanto, la atención que en 2016 Renzo Villata apunte solamente a una sospecha de falsificación y simplemente mencione a Piotti. ${ }^{63}$ Parece que, en muchas ocasiones, no existe un trasvase de información entre los mismos especialistas que se han centrado en este tema. Pensemos que, en 2004, ya circulaban varios estudios sobre esta cuestión y, sin embargo, Giorgetta y Centini seguían considerando Mulier striga un texto auténtico. ${ }^{64}$ Es más, en 2012, Centini sigue defendiendo la misma idea, a pesar de toda la información existente en torno al asunto.$^{65}$ También en 2014 vuelve Ascheri sobre el tema, recalca sus dudas acerca de ciertas obras menores atribuidas a Sassoferrato y se centra especialmente en Mulier Striga.$^{66}$ Por último, es Montesano quien, en un estudio acerca de la cultura clásica y la magia en la Edad Media y el Renacimiento italianos, se refiere al consilium como una falsificación atribuida a Sassoferrato, probablemente del siglo XVI (en su trabajo de 2016 todavía trataba este escrito como auténtico), ${ }^{67}$ pero no parece haber leído a algunos de sus colegas. ${ }^{68}$

$\mathrm{Si}$ en Italia, de donde proceden la mayor parte de materiales en torno a este documento, no ha existido una difusión suficiente de estos descubrimientos, menos lo ha hecho en otros países, como España. En una tesis doctoral de 2016, ${ }^{69}$ por poner un ejemplo reciente, se sigue presentando Mulier striga como un texto fundacional en cuanto a la imagen y el castigo de la bruja, y no se duda de su autenticidad. Esto sucede porque en nuestro país no se conocen las aportaciones de los expertos citados más arriba. En el presente artículo se expone detalladamente esta información, con la finalidad de romper esta "cadena de San Antonio" de la que habla Beccaria, ${ }^{70}$ y dar un paso más allá también en relación con el estudio de este consilium.

El primer estudioso que repara de forma detallada en el falseamiento del documento que nos ocupa es Norman Cohn (1980), como ya hemos señalado. ${ }^{71}$ Entre su trabajo y las posteriores aportaciones de Ascheri y Beccaria encontramos una evolución evidente.

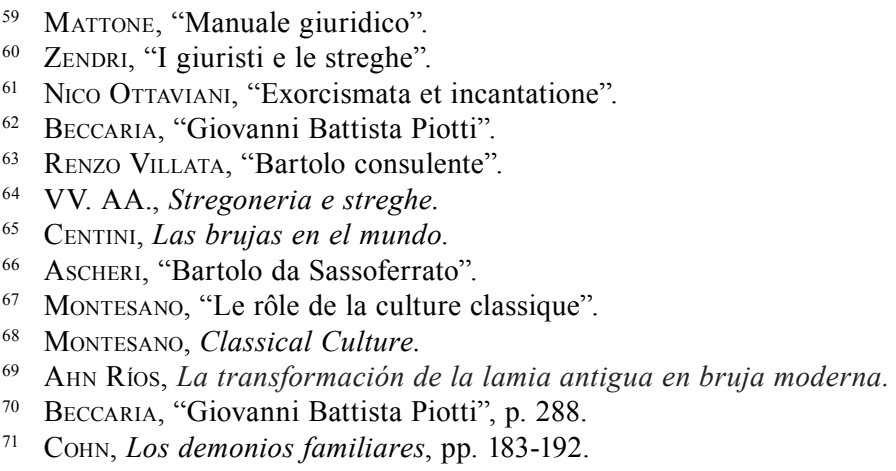


Cohn estaba seguro de que este concilio no era de Bartolo de Sassoferrato ni del período en el que se había datado, a pesar de que nadie lo había puesto en duda y de que figuraba en una gran parte de las historias relativas a la caza de brujas. El texto habría visto la luz en 1566, en la antología de Ziletti, y el autor habría sido el jurista apellidado De Plotis (Piotti), apellido que aparecería en diversos consilia pseudo-bartolianos. Para este especialista, Giovanni Battista Piotti pensó sus textos como una broma, cuestión que será contradicha por todos los datos presentados posteriormente al libro de Cohn. La intención de este jurista del siglo XVI resulta un asunto fundamental a la hora de comprender e interpretar el escrito que nos ocupa.

Los datos más importantes sobre la falsificación de este escrito los aportan Ascheri y Beccaria. Ambos afirman (de acuerdo con Cohn) que el texto comienza a aparecer impreso con la recopilación conciliar criminalística de Ziletti de 1566 y Ascheri señala que en varios consilia Bartolo aparece como consultor de los Piotti (ninguna otra familia habría recibido tanta atención por su parte), operativos en el norte de Italia, cuando él solía operar en Italia central. Este hecho resulta muy llamativo, y hemos de añadir que hay pruebas que confirman la preocupación de Giovanni Battista Piotti por la nobleza y el prestigio de su familia, por lo que este letrado habría tenido como objetivo engrandecer sus orígenes. Este hecho se tendría que sumar a otros factores: el uso de un latín distinto al utilizado por Sassoferrato en otros documentos (ya señalado por Cohn); ${ }^{72}$ una doctrina bartoliana, relativa a cuestiones mágicas, opuesta a la de Santo Tomás (además, los estatutos sinodales de Novara castigaban los sortilegia con la excomunión), por lo que no resulta creíble la aplicación de la pena de muerte; la presencia, por tanto, de un celo contrarreformista impropio de la época, que conectaría con otra posible intención por parte del falsificador, acreditar y defender la máxima punición para la brujería, justo en el marco del debate del siglo XVI, apoyando así una determinada orientación y opinión pública, tras la presunta voz de uno de los juristas más importantes del medievo. ${ }^{73}$

Battista Beccaria, por su parte, aporta detalles de gran relevancia, en lo relativo al papel que ha desempeñado Mulier striga en la tradición (habla de "cadena de San Antonio") y, sobre todo, en referencia a Gionanni Battista Piotti, el impostor, y sus presuntos precedesores, en concreto el obispo de Novara al cual Sassoferrato habría dirigido su consilium sobre la bruja. En el texto aparece como Ioannis Pioti, pero no hubo ningún obispo de tal ciudad así nominado, de modo que se sustituye por Ioannis Visconti, que sí tuvo este cargo en las fechas de datación del documento. Este prelado pasaría a la historia como el primero en llevar a una bruja a la hoguera, lo cual convertiría a este ancestro de nuestro Piotti del XVI en un vir catholicus. La familia Piotti comparece en más consilia, lo cual para este experto es razón suficiente como para ponerlos en duda. Por último, desgrana Beccaria algunos datos acerca del falsificador: tenía fama de falsario e hizo patente su preocupación por los orígenes al

\footnotetext{
CoHn, Los demonios familiares, p. 189.

73 AsCHeri, "Bartolo da Sassoferrato", pp. 211-218.
} 
recalcar en más de una ocasión que procedía de una familia ilustre. Su finalidad con su acto de impostura es, como ya señalaba Ascheri, engrandecer a sus ancestros. Se le califica, además, como reaccionario, sádico e intolerante; de ahí que en un momento en el que los juristas se mostraban escépticos y moderados en cuestiones brujeriles, él se insertara en el debate (a escondidas) para reivindicar la pena de muerte, inclinando la balanza hacia la persecución. ${ }^{74}$

Estos dos especialistas son quienes más han profundizado en esta cuestión, aunque, como hemos visto anteriormente, existen más trabajos que indican la autoría de Gionanni Battista Piotti y respaldan la falsificación, aunque sin la consistencia de las dos referencias mencionadas. De ahí que nos hayamos detenido algo más en ellas. No existe, hoy en día, ninguna duda acerca de las ideas que hemos plasmado. El problema es esa falta de trasvase en la que hemos insistido, tal vez porque la bibliografía que trata esta cuestión no es fácilmente accesible y apenas se conoce. Incluso no ha trascendido, muchas veces, entre los propios estudiosos italianos que citan Mulier striga en sus estudios sobre brujería, como es el caso de Centini. ${ }^{75}$

\section{Una bruja diseñada a conciencia}

Uno de los aspectos que han pasado desapercibidos para los especialistas que hemos consultado en referencia a este texto es la imagen de la bruja plasmada por Piotti. Se han aportado diferentes argumentos a favor de la falsificación y de la autoría de este letrado, como hemos visto. Se ha hablado de anacronismos en el documento, por ejemplo, en relación con el celo contrarreformista al que se refería Ascheri, pero ninguno de los estudiosos se ha detenido en el retrato que se hacía de la striga y en si este resultaba también anacrónico. Esa será nuestra principal aportación.

La mujer que se nos presenta vuela y se conecta con criaturas mitológicas como la lamia latina, lo cual no resulta llamativo porque San Isidoro de Sevilla, en sus Etimologías, hablaba de estos seres en los siguientes términos: "Lamias quas fabulae tradunt infantes corripere ac laniare solitas a laniando specialiter dictas". ${ }^{76}$ También podemos encontrar, en Otia imperialia, cómo Gervasio de Tilbury (c. 1150 - c. 1228) concebía a estas criaturas: "Lamae dicuntur esse mulieres, quae noctu domos momentaneo discursu penetrant, $[\ldots]$ et infantes ex cunis extrahunt, luminaria accendunt et nonnunquam dormientes affligunt". ${ }^{77} \mathrm{~A}$ esta información se añaden más datos en el capítulo LXXXVI del mismo libro, señalando que, según los físicos, estas criaturas son imaginarias y se presentan como fantasías de los durmientes; y para San Agustín serían, en cambio, demonios que

\footnotetext{
BecCaria, "Giovanni Battista Piotti", pp. 283-305.

CENTINI, Las brujas en el mundo.

SAN Isidoro, Etimologías, Libro VIII, sec. 10 De paganis, p. 91.

77 Tilbury, Otia imperialia, Tertia Decisio, cap. LXXXV. Esta definición de lamia también está recogida en Du CANGe, Glossarium mediae.
} 
se presentan en forma femenina. Lo más interesante es que, independientemente de la concepción que se tenga de estos seres, se plasma una creencia existente:

"esse foeminarum ac virorum quorundam infortunia, quod de nocte celeberrimo volatu regiones transcurrunt, domus intrant, dormientes opprimunt, ingerunt somnia gravia, quibus planctus excitant. Sed et comedere videntur et lucernas accendere, ossa huminum dissolvere, quin nonnunquam dissoluta cum ordinis turbatione compaginare, sanguinem humanum bibere et infantes de loco ad locum mutare". ${ }^{78}$

Y a estos entes también se les conoce como mascas o strias, tal y como indica Tilbury. Por tanto, la denominación de striga y lamia responde a la costumbre de identificar a estos seres mitológicos, que resultarían uno solo, con las características ya dichas.

Estas criaturas terminan, además, combinándose con las féminas del cortejo de Diana y Herodiade, aportando sobre todo lo relativo al vampirismo, el infanticidio y otros tormentos a los niños, que se sumarían a la idea de un grupo organizado de féminas que también surcan los cielos de noche. Esto se puede observar ya en el Policraticus de Juan de Salisbury (1158-1159):

"Quale est quod noctilucam quondam vel Herodiadem, vel praesidem noctis dominam con et conventus de nocte asserunt convocare, varia celebrare convivía, ministeriorum species diversis occupationnibus exerceri, et nunc istos ad poenam trahi pro meritis, nunc illos ad gloriam sublimari. Praetera infantes exponi lamiis, et nunc frustatim discerptos, edaci ingluvie in ventrem traiectos congeri, nunc praesidentis miseratione reiectos in cunas reponi". ${ }^{79}$

Aunque esta segunda concepción de cofradía femenina todavía no aparece reflejada en el documento que nos ocupa.

Para Norman Cohn y Michael Bailey, el arquetipo brujeril consta de varios elementos que se combinan y que en un inicio funcionaban por separado, entre ellos está el ser monstruoso que vuela de noche ${ }^{80}$ con base en la strix, no solo como ave, sino más bien como mujer capaz de transformarse en dicha criatura nocturna y vampírica. ${ }^{81}$ Lo más

\footnotetext{
78 Tilbury, Otia imperialia, Tertia Decisio, cap. LXXXVI.

79 Salisbury, Policraticus, p. 83.

80 Conn, Los demonios familiares, p. 193. La bruja como resultado de la confluencia de distintos elementos no es privativa de Cohn, otros estudiosos, como Jean Claude Bologne (De la antorcha a la hoguera, pp. 244ss.), abordan la cuestión en semejantes términos y no olvidan hablar de "la bruja voladora" (pp. 256-259) y combinan la idea del cortejo de Diana con la de la estriga latina. BaILeY, Battling Demons, pp. 32-33.

${ }_{81}$ Cohn, Los demonios familiares, pp. 263-264. CAMPagne (Strix hispánica, pp. 160-201) también afirma que la bruja, como estereotipo, aglutina distintos elementos. Él se centra especialmente en la bruja his-
} 
interesante de las aportaciones de Cohn es que también hace referencia a la creencia germánica en la bruja como fémina cruel y antropófaga, que se refleja, por ejemplo, en la Lex Salica y, posteriormente (ya desde la negación de su realidad), en las leyes de los lombardos promulgadas por el rey Rotario en Pavía en el año 643 y en el capitulario de Carlomagno para los sajones del año 789. A esta mujer se le suponía también la posibilidad de volar de noche.$^{82}$ Igualmente, alude al cortejo de Diana del que hemos hablado (al que dedica todo un capítulo Caro Baroja), ${ }^{83}$ cuya creencia se documenta en Alemania, Francia, Italia... y que conocemos gracias, en gran parte, al Canon episcopi, que no da crédito a esta creencia. No obstante, la actitud comienza a cambiar a partir del siglo XIII. ${ }^{84}$ Para Caro Baroja:

"El siglo XIII es una época de excepcional importancia en la transformación espiritual de Europa. [...] En lo que se refiere a la Magia y a la Brujería, porque durante él puede decirse que se terminó con aquella situación ambigua, mantenida desde el fin del mundo antiguo en punto a la realidad de muchos de los actos atribuidos a las hechiceras y hechiceros [...] y, según la cual, gran parte de los tales eran puramente ilusorios, aunque de origen diabólico". 85

No olvidemos que para Santo Tomás los magos creían dominar a los demonios, pero realmente eran engañados por ellos. La relación entre el oficiante y los diablos se establecía en virtud de un pacto, lo cual implicaba adoración de estos, y la acción diabólica no era ilusoria, sino real. ${ }^{86}$

Una vez establecida esa realidad del trato diabólico y las acciones de los demonios, el escenario ya está listo. Boureau considera que la demonología queda totalmente definida entre 1280 y $1330 .{ }^{87}$ Russell expone que en 1300 los elementos básicos para que se consolide la bujería ya están establecidos, aunque la caza de brujas no comenzaría hasta 1450 aproximadamente, dato que ha sido contradicho por otros expertos, como Ostorero y Bailey, ${ }^{88}$ que hablan más bien de 1430. Según Troncarelli, la bruja se de-

pánica, pero resulta interesante mencionar, igualmente, las creencias que se combinan para dar lugar a una nueva figura: demonio nocturno infanticida, aparecido-vampiro, cortejo de las hadas, demonio de la pesadilla y la mitología del doble. Complementa, así, lo aportado por Cohn, que es el experto que mejor ha sabido explicar la conformación de la bruja.

82 Conn, Los demonios familiares, pp. 265-267.

83 Caro Baroja, Las brujas y su mundo, pp. 85-95.

84 Cohn, Los demonios familiares, pp. 269-278.

85 Caro Baroja, Las brujas y su mundo, p.109.

86 Caro Baroja, Las brujas y su mundo, p.109; Cardini, Magia, brujería y superstición, pp. 41-43; Blázquez Miguel, Eros y Tánatos, p. 16; Tausiet, Ponzoña en los ojos, p. 49; Mérida, El gran libro de las brujas, pp. 19-20.

87 Boureau, Satan hérétique.

88 Russell, A history of witchcraft, p. 72; Ostorero, "Décrire le sabbat", p. 27; Bailey, "From Sorcery to Witchcraft”, p. 90 
sarrolla entre los siglos XII y XIII modificando la imagen del cortejo de Diana. ${ }^{89}$ Eso sí, esta figura estará totalmente constituida, como ente terrorífico y susceptible de ser perseguido, en $1400 .^{90}$

Tiene sentido, según lo visto hasta ahora, que en la primera mitad del siglo XIV se presente en el presunto texto de Sassoferrato a una mujer voladora que se identifica con la strix y la lamia.

Para Russell, el paso de la lamia y la estriga a la bruja se sintetiza de este modo:

"The law helped transfer the characteristics of evil spirits to human witches. The pagans had set out offerings of food and drink for minor spirits. The Synod of Rome in 743 assumed that these spirits were demons and outlawed the offerings. The demonic spirits were then transformated into bonae mulieres, the ghostly "good women" who wandered out at night going into houses and stealing food. Finally, the bonae mulieres were transformated into witches. Likewise, the term striga or stria, originally a blood-drinking night spirit, became a common word for a witch". ${ }^{91}$

Esta imagen es, precisamente, la que refleja Martín Pérez en su Libro de las confesiones (1312-1317), donde habla de "mugeres que se tornan bruxas" e que salen de noche e andan por los ayres e por las tierras e entran por los foracos e comen e chupan las criaturas". ${ }^{93}$ Eso sí, mantiene el escepticismo en estas cuestiones y recuerda que la pena por creer en esta posibilidad es una penitencia que oscilaría entre los cuarenta días y los siete años, basándose en el Decreto de Graciano. Y Bernardo Gui, en su Practica inquisitionis heretice pravitatis (compuesto entre 1321-1324), se detiene en "Interrogatoria ad sortilegos et divinos et invocatores demonum", con relación a los cuales menciona algunos de los actos que les son atribuidos. No se habla todavía de brujería, pero resulta interesante que, entre otras cuestiones como causar esterilidad, dar a comer pelos y uñas, pronunciar conjuros o fabricar imágenes, encontremos una mención a mujeres "quas vocant bonas res que, ut dicunt, vadunt de nocte". ${ }^{94}$

Sigamos con el consilium. Desde un primer momento, se defiende para la striga la pena máxima y eso la define como altamente perniciosa, antes de que se sumen más características a su retrato. A continuación, se aportan más detalles con el objetivo de justificar el castigo que se reclama. En primer lugar, se explica someramente que

\footnotetext{
89 TroncARELl, Le streghe, p. 25.

90 Bailey, Battling Demons, p. 32.

91 Russell, A history of witchcraft, p. 53.

92 Campagne, Strix hispánica, p. 206 afirma que, originalmente, Martín Pérez no hablaba de brujas, sino simplemente de mujeres que van por los aires. En versiones posteriores es cuando comienza a aparecer el término "bruxa".

93 PÉrez, Libro de las confesiones, Parte III, cap. 53, p. 608.

94 GuI, Practica inquisitionis, V parte, cap. VI, punto 2, p. 292.
} 
renuncia a Cristo y el Bautismo; a lo cual se añade que no tiene escrúpulos a la hora de pisotear y escamotear objetos sagrados. Del mismo modo, adora al diablo, prosternándose. En la bula de Juan XXII Super Illius Specula de 1326 se reflejaba la idea del pacto, la adoración y los sacrificios al demonio (no en referencia a la brujería de manera concreta, pues no se contempla en la bula, se habla de magia ritual en general). ${ }^{95}$ Será Johannes Nider en su Formicarius (1437-1438) quien facilite muchos más detalles y ejemplos. Él se detiene en la reunión donde se ve al diablo y ante el cual se reniega y se pisotea la cruz. Nider presenta una concepción de la brujería más evolucionada, en la que ya está presente, aunque de forma sencilla, el conventículo. ${ }^{96}$

Resulta, en consecuencia, totalmente pertinente atribuir estos comportamientos a la bruja del texto, sin hacer referencia a reuniones ni a otros aspectos que se desarrollarían más adelante.

Por otra parte, esta mujer vampiriza a los infantes y los embruja, causando estragos a su paso, tal y como corresponde a la actuación de una lamia. Estas características se asocian a la idea del vuelo que aparece en un inicio, en relación con la bruja antropófaga y nocturna, que terminará fundiéndose con el cortejo de Diana. A pesar de no aparecer unificadas en el documento, hay que tratarlas conjuntamente, tal y como hemos visto con anterioridad. Y es necesario también, llegados a este punto, llamar la atención sobre el hecho de que no se habla de grupo organizado, no se señala que la bruja pertenezca a una secta. Este retrato, rudimentario y perfilado a partir de unos pocos rasgos, todavía presentaba a una mujer que actuaba individualmente, aunque recogía características tanto del monstruo nocturno como del séquito de Diana (otorgándole carta de naturaleza y alejándose del escepticismo de siglos anteriores). En referencia a esto, no podemos olvidar que Cohn ${ }^{97}$ considera los siglos XIV y XV decisivos en cuanto a la combinación de ambas fantasías, que darían lugar a una masa organizada de brujas voladoras que realizaban orgías canibálicas y dirigidas por los demonios. Lo mismo sucede en el caso de Campagne. ${ }^{98}$ Para María Lara también la decimocuarta centuria resulta crucial en referencia con los atributos de la bruja. ${ }^{99}$

Y hemos de tener en cuenta que esta bruja es capaz de matar con la sola mirada o con el tacto. Martín Pérez, en el Libro de las confesiones que ya hemos citado, se refiere a la creencia de que "por aojado que la vista o el oyr de algunas cosas pueden malfazer e por ende se van escantar" 100 y la penaliza, como hacía con lo relativo a las mujeres voladoras, vampíricas y antropófagas; habla de un año de penitencia, remitiéndose siempre al Decreto de Graciano.

\footnotetext{
${ }_{95}$ Boureau, Satan hérétique, cap. 1, pp.17-60, otorga un papel capital a Juan XXII en el ámbito de la demonología, dado que el culto al demonio constituirá una herejía.

96 NIDER, Formicarius, caps. 3-7.

97 Cohn, Los demonios familiares, p. 279.

98 Campagne, Strix hispánica, p. 206.

99 Lara, Brujas, magos e incrédulos, p. 73.

100 Pérez, Libro de las confesiones, Parte III, cap. 53, p. 608.
} 
Para María Tausiet, "la influencia y el poder atribuidos a las brujas, se reflejaban claramente en la doctrina de la fascinación. [...] Brujas eran quienes tenían ponzoña en los ojos y, por tanto, no necesitaban valerse de ningún tipo de veneno o instrumento material para lograr sus perversos fines". ${ }^{101}$ Además, esta cuestión conecta directamente con la posibilidad del maleficio, una práctica mucho más antigua y temida que la brujería, como bien señala Norman Cohn. Este experto, que es quien más se ha centrado en este asunto, documenta casos de maleficium del siglo VI al XIII en reinos germánicos y, entre otras cosas, se usaban estas prácticas para causar la enfermedad o la muerte. En consecuencia, hubo medidas legales, por ejemplo, en Pactus Legis Salicae del siglo VI, la Lex Ribuaria del siglo VII, o el Decretum o Collectarium de Bucardo del siglo XI, en concreto el Libro XIX, conocido como Corrector o Medicus. Cabe destacar que, en este último, se dice que había mujeres que afirmaban ser capaces de matar animales con una palabra o con la sola mirada. Algo muy parecido se afirma de nuestra mulier striga. Cohn insiste en que muchos modos de maleficio de los juicios por brujería de los siglos XV, XVI y XVII habían sido conocidos muchos siglos antes. Otro asunto importante que señala es que ya la iglesia primitiva consideraba las acciones mágicas como manifestaciones paganas, cosa que, a su vez, se vinculaba con la adoración de demonios. Además, a partir del siglo VI, por influencia eclesiástica, se comenzó a tratar cualquier clase de magia como ofensa criminal. En la Alta Edad Media, las autoridades civiles actúan bajo el auspicio de la iglesia en la persecución y sanción del maleficio como transgresión religiosa. ${ }^{102}$

Sin embargo, el maleficio iría viéndose bajo una nueva luz en el marco de la magia ritual que fue lo que en realidad comenzó a preocupar. En los siglos XIII y XIV, según Cohn, ${ }^{103}$ los casos hallados se refieren a la magia ceremonial, a la que terminarían vinculándose las prácticas de maleficium. De hecho, a través de este tipo de actos se podía causar también la enfermedad o muerte. Lo más relevante es, no obstante, que los demonios participan de forma más directa en estos rituales, tal y como se puede ver en el Practica inquisitionis hareticae pravitatis de Bernardo Gui. ${ }^{104}$ Según Pau Castell, Gui se detiene en prácticas de magia popular, junto con invocaciones y sacrificios al diablo, de carácter herético, formando parte del concepto general del maleficium; ${ }^{105}$ lo cual es también resaltado por Bailey. ${ }^{106}$ Para él, esta práctica resultaría clave en la conformación de la brujería y, en el momento de la persecución, adquiriría un nuevo significado, puesto que las brujas actuaban, dañaban, con el auxilio de los demonios. ${ }^{107}$ Estas prácticas, ya de carácter diabólico, habían llamado la atención del Papa Juan XXII desde 1320, y este interés desembocaría en la promulgación de la bula que ya hemos mencionado en varias ocasiones a lo largo de este trabajo, Super Illius Specula. Contra lo que algunos expertos

\footnotetext{
101 TAusiet, Ponzoña en los ojos, p. 30.

102 Conn, Los demonios familiares, pp. 194-208.

103 Conn, Los demonios familiares, pp. 215-228.

104 GuI, Practica inquisitionis, Parte V, cap. VI, punto 2, p. 292.

105 Castell, Orígens i evolución, p. 67.

106 BAILey, "Bernard Gui", p. 465.

107 BAILEy, "From Sorcery to Witchcraft", pp. 961-962.
} 
afirman (como Centini) ${ }^{108}$ no se habla todavía de brujería en este documento, sino de magia de carácter ceremonial. ${ }^{109}$ Hay que tener en cuenta también, en este sentido, que para Bailey se había dado un hecho fundamental que marcaría el camino hacia la brujería, la confusión entre la nigromancia y lo que él llama "demonic sorcery", es decir, entre creencias de carácter culto y de carácter popular, de modo que la hechicería se tratará o concebirá de modo similar al de la magia ritual. La concepción sobre este asunto había mutado a finales del siglo XIII y principios del XIV y se reflejó en la aludida bula: ${ }^{110}$

"Hemos sentido con dolor [...] que hay muchos cristianos sólo de nombre que [...] se dañan y cierran un pacto con el infierno: de hecho, realizan sacrificios a los demonios, los adoran, les construyen o hacen construir imágenes; a ellos piden anillos o espejos o ampollas u otros objetos para evocarlos instantáneamente a través de la magia; a ellos piden ayuda para satisfacer malvados deseos y reciben consejos...

Nosotros promulgamos una sentencia de excomunión contra todos aquellos que individual y colectivamente hayan osado cumplir una sola de estas cosas contra nuestras órdenes y nuestras advertencias y establecemos que ellos incurran inmediatamente en excomunión, sancionando con firmeza que, además de las penas ya indicadas contra aquellos que, debidamente amonestados, a los ocho días de las advertencias no se hayan corregido, se proceda a infligirles las penas, además de la confiscación de los bienes, que la ley prevé para los herejes..."111

Hasta el siglo XIV, según Cohn, ${ }^{112}$ los juicios se habrían dirigido a infractores particulares, que actuaban en solitario, y posteriormente ya comenzarían a integrarse en cofradías organizadas. Este hecho resulta crucial en referencia a Mulier striga, texto en el que no se menciona, como hemos adelantado, la pertenencia a ningún grupo ni una actuación colectiva. Estaríamos aún en el punto de una acusación contra un criminal que actuaba aisladamente. También Pau Castell ${ }^{113}$ constata que es en la decimocuarta centuria cuando se produce una considerable extensión de la noción de complot diabólico, inicialmente en relación con, por ejemplo, judíos o leprosos, más que con brujas. Y menciona dos casos particularmente llamativos y tempranos, el de Cataluña en 1313 contra una mujer sospechosa de la profanación de un cadáver infantil con el fin de usar sus miembros en actos mágicos y el de Alice Kyteler (mencionada también por Cohn

\footnotetext{
108 Centini, Las brujas en el mundo, s. p.

109 BAILEY, "Bernard Gui", p. 465, insiste también, en relación con el tratado de Gui, en que nunca describe el estereotipo brujeril, pero se centra en actos mágicos determinantes para la conformación de la brujería.

110 BAILEy, "From Sorcery to Witchcraft", pp. 963-966.

111 TroncARelLi, Le streghe, pp. 95-96, traducción propia.

112 Cohn, Los demonios familiares, pp. 252-253.

113 Castell, Orígens i evolución, p. 67-70.
} 
y Martin), ${ }^{114}$ entre 1324-1325, en Irlanda, acusada de maleficio, apostasía, adoración al diablo y con alusión a una secta.

No parecería extraño, por tanto, que entre 1331 y 1334 se hubiera procesado a una bruja en Orta con los atributos que se le adjudican en el concilio pseudo-bartoliano, dado que asistimos a la integración del trato diabólico en la práctica del maleficio, y a la fusión de estos dos elementos con la imagen de la striga-lamia voladora y chupasangre. Si bien la caza de brujas se inicia, principalmente, de 1420 en adelante, tal y como atestiguan Ostorero, quien señala que existen procesos judiciales antes de $1430,{ }^{115}$ por ejemplo, el caso de Valais de 1428 expuesto por Hans Fründ, que sería el primero en describir el sabbat; ${ }^{116}$ y Kieckhefer, que se centra en varios procesos sucedidos en Lausanne desde 1438, pero afirma que existe documentación acerca de juicios en otras regiones a partir de $1430 .{ }^{117}$

Nos hallamos, en definitiva, ante el tosco retrato de una bruja, perfilado a partir de unas pocas características, una imagen que no incluye apenas detalles, y que de manera intencionada no recoge ningún dato acerca del aquelarre. Si todavía en el Malleus maleficarum se encuentra poco desarrollada la idea de la reunión nocturna presidida por el demonio, sería impensable que se hiciera hincapié en este aspecto de la secta en los años 30 del siglo XIV. De hecho, no se habla aún, y eso resulta hartamente llamativo, de grupo organizado, de secta. Estamos todavía ante la individualidad de la bruja, que renuncia a la fe y adora al diablo, pero de la cual no se señala que pertenezca a ninguna cofradía o hermandad. Esa descripción, en cierto modo rudimentaria, se ha diseñado con sumo cuidado, atendiendo bien a qué rasgos podían o no podían incluirse. Giovanni Battista Piotti debía de conocer tratados de la talla del Formicarius ${ }^{118}$ (el segundo texto que describe la reunión, tras lo que exponía Hans Fründ al respecto), ${ }^{119}$ o del Malleus maleficarum ${ }^{120}$ además de otros escritos; si mencionamos estos dos textos es por su carácter representativo, no podía perfilarse la imagen de esta mulier striga sin atender a lo dicho por Nider, y Sprenger e Institoris.

El consilium es un documento muy breve, por lo que no podía desarrollar las ideas, solo exponerlas de forma esquemática y esgrimir sobre todo los argumentos, con las citas a las autoridades pertinentes, para defender la aplicación de la pena capital. No cabían anécdotas ni ejemplos, de ahí que sea en los tratados donde los intelectuales tienen la posibilidad de ofrecer experiencias y relatos que contribuyen a engrandecer y completar la visión que de la bruja se plantea. Igualmente, había que evitar hacer refe-

114 Cohn, Los demonios familiares, p. 253; Martin, Witchcraft, pp. 41-44.

115 Ostorero, "Décrire le sabbat", p. 27.

116 Ostorero, "Décrire le sabbat", p. 31. Véase también Ostorero, Paravicini, utz tremp (coords.), L'imaginaire du Sabbat, donde se ofrece la traducción y edición de este y otros textos tempranos que reflejan el conventículo, como el Formicarius (1436-1438), Errores Gazariorum (c. 1436) y Champion des Dames (1440-1442).

117 KiecKhefer, "Mythologies of Witchcraft", pp. 80 y 94.

118 NIDER, Formicarius.

119 Ostorero, "Décrire le sabbat", p. 31.

${ }^{120}$ SPREnGER; InSTITORIs, Malleus maleficarum. 
rencia a aspectos que no se mencionaban o que estaban aún pobremente especificados en manuales que, presuntamente, se habían escrito más de un siglo después.

La bula de Juan XXII, de 1326, solo aludía, de forma general y sin focalizar en un grupo de mujeres que servían al demonio, a la costumbre de algunos cristianos de cerrar un pacto con el diablo y de adorarle, construyéndole incluso imágenes o pidiéndoles anillos o figuras a través de las cuales invocarlos para satisfacer sus deseos. No se habla todavía de brujas. No era concebible, por tanto, que Sassoferrato profundizara más en estas cuestiones. En cambio, sí tenía sentido, y mucho, encontrar en este texto el eslabón que permitía conectar el Canon episcopi (con su cortejo de Diana, creencia que era duramente condenada), y también el Policraticus (que muestra la evolución o el recrudecimiento de lo expuesto por el Canon al hablar de sacrificios de niños a las lamias, y que mantiene la actitud escéptica) con los primeros tratados demonológicos. Giovanni Battista Piotti, en un ejercicio de creación, parece estar fusionando el cortejo de Diana, las lamias a las que ya aludía Salisbury, y la idea del pacto, el reniego y la profanación de objetos sagrados, sin olvidar el maleficium. Por ello, el documento se tomaba como un texto fundacional, no solo desde un punto de vista jurídico, sino también desde un prisma antropológico.

No obstante, no creemos que el resultado final fuera ajustado al milímetro por este jurista del siglo XVI. Seguramente, confeccionó el retrato, en alguno de sus rasgos, de forma intuitiva, y no siempre desde el conocimiento profundo del fenómeno de la brujería, ni desde la lectura meticulosa de todas las obras escritas hasta la fecha de composición de la falsificación. Pero sí acertó al sumar el peligro del maleficio a los demás actos de la bruja, dado que las prácticas mágicas capaces de causar daño o la muerte ya eran condenadas en multitud de leyes, como hemos visto anteriormente, que el letrado conocería.

No sería así para Norman Cohn, ${ }^{121}$ quien afirma que Piotti simplemente se habría inspirado o basado en el Tractatus de strigiis del inquisidor de Como, Bernardo Rategno. Este escrito fue compuesto hacia 1508, pero no vio la luz hasta 1566 en Milán, como apéndice de su Lucerna Inquisitorum. Cierto es que Rategno ${ }^{122}$ atribuía a las brujas las características que observamos en Mulier striga, aunque junto a muchísimas otras, dado que en esta obra se profundiza detalladamente en el arquetipo, y no olvidemos que los elementos expuestos por Piotti servían de base a la brujería, no eran privativos de su striga de Orta. En el Tractatus de strigiis hay reniego y se profanan objetos sagrados, pero eso no prueba nada, ya que también se habla ya de un grupo organizado, una secta, y este aspecto no aparece reflejado en el texto pseudo-bartoliano. De entre la multitud de datos aportados por este inquisidor de Como, en todo caso, Piotti habría seleccionado apenas unos pocos, muy básicos, comunes a otros tratados. Más interesante es, si cabe, el hecho de que Rategno indicara que la secta habría comenzado

${ }_{121}$ Cohn, Los demonios familiares, pp. 191-192.
122 Rategno De Como, Tractatus De Strigiis, 
su andadura hacia 1350. Esto sí podría haber dado la idea a Piotti para su concilio, fechado en la primera mitad del siglo XIV.

En consecuencia, tal vez sea cierto que el falsario leyó el tratado de Rategno, publicado en Italia precisamente el mismo año que se editó la antología de Ziletti, pero hemos de tener en cuenta dos cuestiones. La primera es que quizás la obra del inquisidor no llegara a tiempo a las manos de Piotti, dado que ambas publicaciones tuvieron lugar en el mismo año y, considerando las aportaciones de Beccaria, es posible que los consilia falsos aparecieran ya en una reimpresión de la Repetitio legis de Giovanni Battista Piotti, pocos meses después de la edición de Venecia de $1557,{ }^{123}$ con lo cual la lectura del texto del inquisidor no se habría producido antes de la composición y edición del documento. La segunda es que, aun habiéndola consultado, tuvo que decidir igualmente cómo iba a confeccionar su retrato y recordemos que lo hizo de una manera bastante creíble, teniendo en cuenta el lugar que ocuparía entre la doctrina propia del Canon episcopi y las creencias reflejadas en el Formicarius. Además, los actos de la bruja de Orta no desentonaban con lo que criticaba y castigaba la bula de 1326.

Sí podría haber leído las obras de Gianfrancesco Ponzinibio, De lamiis et excellentia utriusque iuris (1515) y Bartolomeo Spina, Quaestio de strigibus (1523) y Quadruplex apologia de lamiis contra Ponzinibium (1525), en el marco de un debate entre dos posturas encontradas, que reflejaría muy bien los distintos prismas imperantes con respecto a esta temática. El primero, jurista precisamente, negaba la realidad de la brujería, cuestionaba especialmente la posibilidad del sabbat y apelaba a la ley, por encima de las doctrinas teológicas. El segundo, dominico con experiencia como inquisidor, refutaba las tesis de Ponzinibio, consideraba viable el traslado corpóreo al conventículo y solo optaba por las ilusiones diabólicas en el caso de las metamorfosis. Para él la brujería debía perseguirse y castigarse, al contrario de lo que exponía su oponente. ${ }^{124}$ Esta discusión, sin duda, avivaría las reflexiones de Piotti y lo posicionarían del lado de la persecución. No obstante, nada sobre reuniones nocturnas ni transformaciones plasma el autor en su texto, alejándose de los contenidos sobre los que se disertaba en esta clase de tratados, como sucedería en el caso del Tractatus de strigiis.

Lo que no se puede negar, a la luz de lo vertido por los expertos que hemos mencionado a lo largo de este trabajo, es que Piotti tenía dos intenciones muy claras a la hora de elaborar este concilio: prestigiar sus orígenes, dado que se emparenta con el obispo de Novara, que es quien solicita el consejo de Bartolo de Sassoferrato, y tomar parte en el debate brujeril del siglo XVI, ocultándose tras el jurista medieval y siendo contundente al reclamar la muerte para las brujas. De acuerdo con su primer objetivo, introduce la figura de Ioannis Piotti / Visconti, y en relación con el segundo se aplica concienzudamente a elaborar una imagen adecuada. Y lo consigue. No sucede así con otras cuestiones, a partir de las cuales se ha podido detectar que Mulier striga no es un consilium bartoliano.

\footnotetext{
${ }^{123}$ Beccaria, "Giovanni Battista Piotti", p. 291.

124 Véase DunI, "Lawyers versus inquisitors".
} 
Por otra parte, cabe destacar que Piotti idea todo un contexto para la redacción del presente escrito, ya que el mismo surge como respuesta a una consulta del obispo de Novara, ya mencionado, acerca de cómo proceder en el caso de una bruja a la que ha de juzgar. En ese sentido, las características que se atribuyen a la bruja en este documento estarían tomadas de una figura real, la denominada "bruja de Orta" y se conocerían como resultado de la confesión de esta mujer. Así que no solo se genera una determinada imagen de la striga, sino que se hace a partir de la invención de un personaje supuestamente histórico. Se hace creer, además, que Ioannis Piotti / Visconti la llevó a la hoguera; de hecho, este obispo pasó a la posteridad como el primero en quemar a una bruja. Hay, en consecuencia, un ejercicio de creación que sobrepasa el propio concilio y alcanza a la realidad circundante, que es moldeada de acuerdo con la voluntad del fasificador. Este último usa una voz impostada para otorgar autoridad a sus palabras y deja bien asentado que dicha autoridad ya tuvo su influencia en un momento determinado y en relación con un caso muy concreto. Se establece así una alianza entre Sassoferrato y los Piotti, un vínculo falaz que no se desmoronará hasta finales del siglo XX, gracias a la labor de estudiosos como Ascheri y Beccaria, sobre todo.

\section{Conclusiones}

En el presente artículo nos proponíamos, por una parte, difundir el hecho de que el concilio denominado Mulier striga, atribuido a Bartolo de Sassoferrato, es una falsificación, ofreciendo un completo estado de la cuestión. Esta certeza, ya demostrada por varios especialistas, ha de propiciar la ruptura de la cadena de transmisión que todavía impera y que presenta este documento como fidedigno y auténtico. Es, por tanto, urgente reivindicar la necesidad de integrar estas evidencias en todos los estudios de la materia brujeril, con la finalidad de presentar un panorama realista y desprovisto de falsedades, en lo que tiene que ver tanto con la concepción de la Edad Media en referencia a la caza de brujas, como con el texto mismo que nos ocupa. Por tanto, a las preguntas planteadas en la introducción: ¿es Mulier Striga el documento que sirve como primera piedra para construir la imagen de la bruja? y ies realmente un escrito tan temprano?, hemos de responder, evidentemente, que ni es tan temprano como se creía a priori ni puede concebirse como uno de los puntales de la imagen de la bruja medieval.

Por otra parte, teníamos también como objetivo ahondar en el retrato de la striga que se presenta en el concilio, pues se trata del aspecto que la crítica ha descuidado hasta el momento, como hemos explicado; aportando así nuestro grano de arena a la indagación en torno a este documento y en relación con el arquetipo de la bruja, que se va consolidando lentamente a lo largo de los siglos. Si bien es cierto que Mulier striga no es un escrito medieval, hemos de tener en cuenta que sí se intenta hacer pasar por tal, y Piotti cuida muy bien su diseño. Un diseño que está basado, además, en la invención de un personaje histórico, una mujer de Orta que ha de ser juzgada por el obispo de Novara, conectando así la teoría con la praxis (falsa, claro está, pues no hay ajusticiamiento 
porque todo es una invención). El ejercicio de creación resulta, sin duda, muy interesante para el estudioso, y aporta una dimensión literaria a la redacción del consilium. Al haber analizado la anatomía de la bruja pseudo-bartolina, hemos dado respuesta también a la cuestión inicial: ¿cuál es el retrato que nos ofrece el texto?

Hemos demostrado, con la contextualización del escrito en los años de su supuesta composición (1331-1334), que los rasgos y actos atribuidos a la bruja no resultan llamativos ni disienten de lo que en aquel momento se consideraba viable, tal y como se muestra en los tratados, leyes y bulas mencionados. En ese sentido, incluso el suavizamiento del tono del que hablan algunos expertos citados, y el hecho de no tomar partida en cuanto al aojamiento o maleficio por el tacto, estaría justificado por lo que en la documentación de la época se señalaba al respecto, pues todavía prevalecía, en algunos casos, el escepticismo. Quizás por eso mismo, el autor considerara la posibilidad del perdón para la bruja si había arrepentimiento y abjuración pública, con el objetivo de no contravenir la legislación imperante, aunque su estrategia resultó fallida, y su juego fue descubierto, eso sí, cuatrocientos años después. Esta parte del estudio aportaba la información necesaria para contestar a ¿dónde radica su originalidad?, pues el documento se diseña para ser creíble, pero también para aportar lo que otros materiales todavía no habrían ofrecido. Dicha singularidad también vendría representada por el hecho de que el texto es una construcción consciente que se genera para integrarse como una pieza pensada, meditada, y fechada en la primera mitad del siglo XIV.

En último lugar, cabe destacar que, aunque nuestro acercamiento al consilium se integraba en una línea de investigación acerca de los antecedentes de la literatura de terror sobrenatural (en un intento de ahondar en los principales puntales de la bruja como arquetipo terrorífico), la indagación tomó otros caminos tras descubrir que el texto era una falsificación. Tomando como base los hallazgos de especialistas de la talla de Cohn, Ascheri o Beccaria, entre otros, determinamos la necesidad de profundizar en aquellas lagunas que la bibliografía presentaba, en torno a la imagen de la striga principalmente. Creemos haber logrado nuestro cometido.

Y a pesar de que el texto se haya de fechar en la segunda mitad del siglo XVI, no se puede negar su interés en relación con el Medievo, ni su relevancia en tanto ha desempeñado un papel fundamental en la tradición. El ejercicio de creación llevado a cabo por Piotti no puede pasarse por alto ni dejarse de lado a la hora de estudiar la documentación existente en relación con la brujería. Estamos ante un concilio falso de 1566, pero que presenta a una bruja primigenia perfilada concienzudamente. En ese sentido, puede seguir analizándose desde un prisma antropológico y desde el punto de vista del terror. Esto último será, eso sí, materia para otros trabajos. 


\section{Obras citadas}

Aвbiati, Sergio; agnoletto, Attilio; lazzati, Maria Rosario, La stregoneria: diavoli, streghe, inquisitori del Trecento al Settecento, A, Mondadori, Milano, 1984.

Ahn Ríos, María Soraya, La transformación de la lamia antigua en bruja moderna. Edición crítica y traducción del 'De lamiis et pithonicis mulieribus'de Ulrich Molitor (1489), Universitat de Barcelona, Barcelona, 2016.

Ascheri, Mario, "Streghe e devianti: alcuni consilia apocrifi di Bartolo da Sassoferrato", Scritti di storia del diritto offerti dagli allievi a Domenico Maffei, Mario Ascheri (ed.), Antenore, Padova, 1991, pp. 203-234.

Ascheri, Mario, "Bartolo da Sassoferrato: introduzione a un giurista globale", Mundos medievales II. Espacio, sociedades y poder. Homenaje al profesor José Ángel García de Cortázar y Ruiz de Aguirre, Universidad de Cantabria, Santander, 2014, pp. 1029-1040.

BecCARIA, Battista, "Giovanni Battista Piotti falsario (1517-1570). L'invenzione della strega di Orta", Novarien: rivista dell'Associazione di Storia della Chiesa Novarese, XLVI, 42 (2013), pp. 283-305.

BAILeY, Michael D., "From Sorcery to Witchcraft: Clerical Conceptions of Magic in the Later Middle Ages", Speculum, 76 (2001), pp. 960-990

Bailey, Michael D., Battling Demons: Witchcraft, Heresy, and Reform in the Late Middle Ages, University Park, Pennsylvania State University Press, 2003.

BAILEY, Michael D., "Bernard Gui", Encyclopedia of Witchcraft. The Western Tradition, Richard M. Golden (ed.), ABC-CLIO, Santa Barbara, 2006, p. 465.

Blaschke, Jorge, El enigma medieval. Los secretos de la Edad Media, Robinbook, Barcelona, 2004.

Blázquez Miguel, Juan, Eros y Tánatos. Brujería, hechicería y superstición en España, Toledo, Arcano, 1989.

Bologne, Jean Claude, De la antorcha a la hoguera, Madrid, Anaya \& Mario Muchnick, 1997.

Bonomo, Giuseppe, Caccia alle streghe. La credenza nelle streghe dal sec. XIII al XIX con particolare referimento all'Italia, Palumbo, Palermo, 1959.

Boureau, Alain, Satan hérétique. Naissance de la démonologie dans l'Occident médiéval (1280-1330), Paris, Odile Jacob, 2004.

Boureau, Alain, Le pape et les sorciers. Une consultation de Jean XXII sur la magie en 1320 (manuscrit B.A.V. Borghese 348), Rome, École française de Rome, 2004.

Campagne, Fabián Alejandro, Strix hispánica. Demonología cristiana y cultura folklórica en la España moderna, Prometeo, Buenos Aires, 2009.

CARdini, Franco, Magia, brujería y superstición en el Occidente medieval, Barcelona, Península, 1982. 
Caro Baroja, Julio, Las brujas y su mundo, Madrid, Alianza, 1995. $1^{\text {a }}$ edición 1966. Castell, Pau, Orígens i evolució de la cacera de bruixes a Catalunya (segles XV y XVI), Universitat de Barcelona, Barcelona, 2013.

Castell, Pau, "L'inquisiteur et ses demons. La démonologie dans la vie et l'oeuvre de Nicolau Eymeric", Cahiers de Recherches Médiévales et Humanistes (en prensa).

Centini, Massimo, Las brujas en el mundo, De Vecchi, Barcelona, 2012.

CoHn, Norman, Los demonios familiares en Europa, Alianza, Madrid, 1980, $1^{\text {a }}$ ed. 1975.

Colli, Gaetano, “Attibuuntur Bartolo et tamen non sunt Bartoli”, Bibliotecario, 1 (1996), pp. 145-191.

Concilvum Ancyrarum (314) Tempore Silvestri Patre Celebratum. Probatum a Leone iv. d. 20c. de libellis. Vt episcopi de parochiis suis sortilegos \& maleficos expellant, en Labbei, Philip; Cossartii, Gabr., Sacrosanta Concilia ad Regiam Editionem exacta quae nunc quarta parte prodit auctior, Tomi i. Pars i, 33-324, Lutetiae Parisiorum, Impensis Societatis Typographicae Ecclesiasticorum jussu Regis Constitutae. Cum privilegio regis christianissimi, 1672 (Biblioteca Apostólica Vaticana), pp. 1476-77.

Du CANGE et alii, Glossarium mediae et infimae latinitatis, L. Favre, Niort, 1883-1887, $1^{\mathrm{a}}$ ed. 1678.

Duni, Matteo, “Lawyers versus inquisitors: Ponzinibio's De lamiis and Spina's De strigibus, The Science of Demons. Early Modern Authors Facing Witchcraft and the Devil, Jan Machielsen (ed.), London and New York, Routledge, 2020, pp. 68-82.

Eymerich Nicolás; PeñA, Francisco, El manual de los inquisidores, ed. Luis Sala-Molins, Muschnik, Barcelona, 1983.

Giralt, Sebastiá, "Magia y ciencia en el Baja Edad Media: La construcción de los límites entre la magia natural y la nigrogmancia (c. -1230c. 1310)”, Clío \& Crimen, 8 (2011) (monográfico Magia, superstición y brujería en la Edad Media, Iñaki Bazán Díaz (ed.), pp. 14-72.

Grimm, Jacob, Theutonic Mythology, vol. III, London, George Bell \& Sons, 1883.

Gui, Bernardo, Practica inquisitionis heretice pravitatis, Alphonse Picard, París, 1886. Hansen, Joseph, Quellen und untersuchungen zur geschichte des hexenwahns und der hexenverfolgung im mittelalter. Mit einer untersuchung der geschichte des wortes hexe, Carl Georgi, Universitäts Buchdruckeler un Verlag, Bonn, 1901.

IrIBARREN, Isabel, "From Black Magic to Heresy: a Doctrinal Leap in the Pontificate of John XXII”, Church History, 76 (2007), pp. 32-60.

IzBICKI, Thomas; Lally, Patrick, "Texts attribuited to Bartolus de Saxoferrato in North American Manuscript Collections", Manuscripta, 35 (1991), pp. 146-155.

KieCKHEFER, Richard, La magia en la Edad Media, Crítica, Barcelona, 1992.

KonIng, Frederik, Historia del satanismo, Bruguera, Barcelona, 1975. 
LANCre, Pierre de, Tableau de l'inconstance des mauvais anges et demons, Chez Iean Berjon, París, 1612.

LARA, María, Brujas, magos e incrédulos en la España del Siglo de Oro. Microhistoria cultural de ciudades encantadas, Cuenca, Alderabán, 2013.

LARA, María, Pasaporte de bruja: volando en escoba de España a América, en el tiempo de Cervantes, Cuenca, Alderabán, 2016.

LARA Alberola, Eva, Hechiceras y brujas en la literatura española de los Siglos de Oro, Universitat de València, Valencia, 2010, col. Parnaseo.

LEA, Henry C. y Howland, Arthur, Materials toward a history of witchcraft, University of Pennsylvania Press, Philadelphia, 1939.

LOVECRAFT, Howard Phillips El horror sobrenatural en la literatura y otros escritos teóricos y autobiográficos, Valdemar, Madrid, 2010 ( $1^{\text {a }}$ ed. 1927).

Martin, Lois (2010): Witchcraft. A brief history of Demons, Folklore and Superstition. London: Robinson.

Mattone, Antonello, "Manuale giuridico e insegnamento del diritto nelle università italiane del XVI secolo,Diritto@Storia, 6 (2007), http://www.dirittoestoria.it/6/Contributi/Mattone-Manuale-giuridico-insegnamento-universit-XVI-secolo.htm [12 de mayo de 2019].

MÉRIDA JimÉnez, Rafael, El gran libro de las brujas, Barcelona, RBA, 2004.

Montaner, Alberto y LARA, Eva, "Magia, hechicería, brujería: deslinde de conceptos", Señales, portentos y demonios: La magia en la literatura y la cultura españolas del Renacimiento, Eva Lara y Alberto Montaner (eds.), Sociedad de Estudios Medievales y Renacentistas, Salamanca, 2014, pp. 33-184.

Montesano, Marina, "Le rôle de la culture classique dans la définition des maleficia. Una démonologie alternative?", Sorcières et démons (15e-17e s.), Firenze, Simel-Edizioni del Galluzzo, pp. 103-118.

Montesano, Marina, Classical Culture and Witchcraft in Medieval and Renaissance Italy, Palgrave Macmillan, London, 2018.

Nico Ottaviani, Maria Grazia, "Exorcismata et incantatione nella legislazione statutaria umbra dei secoli XIII-XVI", Non lasciar vivere la malefica: le streghe nei tratatti e nei processi (secoli XIV-XVII), Dinora Corsi y Matteo Duni (eds.), Università degli Studi di Firenze y New York University in Florence, Firenze, 2008, pp. 45-52.

Nider, Johannes, El libro quinto del Formicarius, ed. Pedro Eduardo León Mescua, s. e., Valencia, 2019.

Ostorero, Martine; Paravicini, Agostino; Utz Tremp, Kathrin (coords.), L'imaginaire du sabbat. Édition critique des textes les plus anciens (1430 c.-1440 c.), Lausanne, Université de Lausanne, 1999.

Ostorero, Martine, "Décrire le sabbat. Les textes des années 1430-1440”, Sorcières et démons (15e-17e s.), Firenze, Simel-Edizioni del Galluzzo, pp. 3-54. 
PÉrez, Martín. Libro de las confesiones. Una radiografía de la sociedad medieval española, ed. Antonio García y García, Bernardo Alonso Rodríguez y Francisco Cantelar Rodríguez, Biblioteca de Autores Cristianos, Madrid, 2002.

Pseudo-Sassorferrato, Bartolo de, "Consilia XXXIIII tan civilia, quam criminalia Bartoli a Saxoferrato", Bartoli a Saxoferrato, Omnium Iuris Interpretum Antesignani. Consilia, quaestiones et tractatus. Tomus Decimus, Iacobi Anelli de Bottis, Venetiis, 1596 ( $1^{\mathrm{a}}$ ed. consilia falsificados 1566).

Rategno da Como, Bernardo, Tractatus De Strigiis, apéndice de Lucerna inquisitorum haereticae pravitatis, apud Marcum Antonium Zalterium, Venetiis, 1596, $1^{\text {a }}$ ed. 1566.

Renzo Villata, Maria Gigliola di, "Bartolo consulente nel 'penale': un'auctoritas indiscussa?, Bartolo da Sassoferrato nella cultura europea tra Medioevo e Rinascimento, Victor Crescenzi e Giovanni Rossi (eds.). Istituto Internazionale di Studi Piceni Bartolo da Sassoferrato, 2016, pp. 25-62.

Río, Martín del, Disquisitionum Magicarum, Sumptibuus Hermanni Demen, Coloniae Agrippinae, 1679, $1^{\text {a }}$ ed. 1599.

Russell, Jeffrey B. (1981): A history of witchcraft. Sorcerers, Heretics and Pagans. London: Thames and Hudson.

SALINAS DE FRÍAS, Manuel, "Tradición y novedad en las leyes contra la magia y los paganos de los Emperadores cristianos", Cristianismo y aculturación en tiempos del Imperio Romano, Antonino González Blanco y José Ma . Blázquez Martínez (eds.), col. Antigüedad y Cristianismo, vol. VII, Universidad de Murcia, Murcia, 1990, pp. 237-246. Salisbury, Juan de, Policraticus, Lugduni Batavorum, Ioannis Maire, 1639.

SAN IsIDORO, Etimologiae, https://www.wdl.org/es/item/14705/ [6 de septiembre de 2019]. SANTANGelo, Angela, "Mulier-striga, I tratatti sulla stregoneria tra Quattro e Cinquecento: la Lucerna inquisitorum di Bernardo Rategno da Como, Rivista Internazionale di diritto comune, 22 (2011), pp. 117-140.

Semeraro, Martino, Il tribunale del Santo Officio di Oria: inediti processi di stregoneria per la storia dell'inquisizione in età moderna, Giuffré, Roma, 2003.

SPRENGER, Jacobo; Institoris, Enrique El martillo de las brujas (Malleus Maleficarum), Maxtor, Valladolid, 2004 ( $1^{\mathrm{a}}$ ed. 1487).

TARTARotti, Girolamo, Del congresso notturno delle lamia libri tre, Giambatista Pasquali, Venezia, 1749.

Tausiet, María, Ponzoña en los ojos. Brujería y superstición en Aragón en el siglo xvi, Zaragoza, Institución Fernando el Católico, 2000; Madrid, Turner, 2004.

Tilbury, Gervasio de, Otia imperialia, Von Felix Liebrecht, Carl Rümpler, Hannover, 1856, https://archive.org/details/desgervasiusvon01liebgoog/page/n8 [3 de octubre de 2019].

Troncarelli, Fabio, Le streghe: Tra superstizione e realtà. Storie segrete e documenti inediti di un fenomeno tra i più inquietanti della società europea, Roma, Newton Compton, 1983. 
VÉRONĖSE, Julien, "Nigromancie et hérésie: le De jurisdictione inquisitorum in et contra christianos demones invocantes (1359) de Nicolas Eymerich (O.P.)", Penser avec les demons: Démonologues et demonologies, XIIIe-XVIIe siècles, Martine Ostorero and Julien Véronèse (eds), Florence, Sismel-Edizioni del Galluzzo, 2015, pp.5-56.

VV. AA., Memorie dell'I. R. Istituto Lombardo di scienze lettere ed arti, V. II., Tipografia Bernardoni, 1845.

VV.AA., Biblioteca Lamiarum. Documenti e immagini della stregoneria del medio Evo all'età moderna. Mostra bibliografica e documentaria, Pacini Editori, Pisa, 1994.

VV.AA. Stregoneria e streghe nell'Europa moderna. Convegno internazionale di studi (Pisa, 24-26 marzo 1994), Ministerio per i beni Culturali e Ambientali. Ufficio centrali per i beni librari, le istituzioni culturali e l'editoria. Biblioteca Universitaria di Pisa, 1996. ZENDRI, Christian, "I giuristi e le streghe: a proposoto del consilium 'Mulier striga', attribuito a Bartolo da Sassoferrato", Annali dell'Istituto Storico Italo-germanico in Trento, 33 (2007), pp. 11-26.

Zerner, Monique, "Herejía”, Diccionario razonado del Occidente medieval, Jacques Le Goff y Jean Claude Schmitt (eds.), Akal, Madrid, 2003, pp. 328-339. 